\title{
CONSUMER ATTITUDE, SATISFACTION, FOOD SAFETY AWARENESS, AND PURCHASE INTENTION OF FOOD ORDERED THROUGH ONLINE FOOD DELIVERY USING MOBILE APPLICATION IN PENANG ISLAND, MALAYSIA
}

\author{
SITI NUR ZULAIKHA SHAFIEE ${ }^{1}$ and MOHAMAD RAHIJAN ABDUL WAHAB ${ }^{1,2}$ \\ ${ }^{1}$ Faculty of Fisheries and Food Science, Universiti Malaysia Terengganu, \\ 21030 Kuala Nerus, Terengganu, Malaysia \\ ${ }^{2}$ Faculty of Health Sciences, Department of Nutrition \& Dietetics, \\ Universiti Sultan Zainal Abidin, 21030 Kuala Nerus, Terengganu, Malaysia \\ *E-mail:rahijan@umt.edu.my
}

Accepted 14 October 2021, Published online 30 November 2021

\begin{abstract}
People can order meals and deliver them to their homes, offices, or other locations using the internet. A meal delivery app allows users to order food online and deliver it to their homes or office. It may become an issue in Penang as more people use meal delivery apps rather than stores or premises. As a result, this study aimed to provide restaurant owners with new ideas or methods to increase their offline and online clientele while raising consumer awareness of food safety. The study's main objectives are customers' satisfaction, food safety awareness, and the intent to purchase food using meal delivery apps on Penang Island. This study took place on Penang Island. A survey of 160 people yielded the data. The data was analyzed using SPSS 20. The $r$-value of 0.708 between consumer happiness and food safety awareness shows a significant positive relationship. However, monthly income and customer purchase intent differ significantly $(p=0.005)$. There is also a significant difference between age group and purchase intention $(p=0.001)$ and marital status ( $p=0.023)$. Finally, there is a significant difference between occupation and consumer attitudes $(p=0.025)$ and consumer awareness of food safety $(p=0.032)$.
\end{abstract}

Key words: Attitude, delivery apps, food delivery, food safety awareness, purchase intention, satisfaction

\section{INTRODUCTION}

Penang, sometimes known as "Penang Island," is a well-known state in Malaysia, located on Peninsular Malaysia's north-western coast. Penang is renowned among Malaysians and tourists for its multicultural past, including people of all ethnicities living together, such as Malay, Chinese, and Indians. The most common reason visitors visit Penang is for its food and as a vacation location, as Penang is renowned as "Food Paradise." Many various delectable food varieties are available in Penang from a different kind of culture that delights everybody who tries it. Because there is so much food sold in Penang, the demand for it is enormous, and people come up with the notion of ordering food online because it is more convenient and accessible. Food delivery applications allow users to get a wide range

* To whom correspondence should be addressed. of foods from many restaurants with a single tap on their smartphones. Customers can purchase food from various eateries using their smartphones through online food delivery (Kapoor \& Vij, 2018). Customers can avoid walking to a café or restaurant to buy food by using delivery applications. Instead, they will sit at home or work and begin placing an order, saving time by not waiting in line at a restaurant to place an order because their time is restricted. However, some restaurants would appear vacant or without customers, and tourists may adversely react to certain cuisine establishments in Penang. One of the worries in Penang may be the growing number of meal delivery applications. The number of customers that visit a restaurant or food establishment will drop, which will have a detrimental impact on the restaurant's atmosphere, as the atmosphere created by guests, their conversations, and the clinking of glasses and silverware. A restaurant or food outlet will draw people with a large 
number of patrons or customers. As more individuals prefer to buy food online, fewer people will be at food establishments, making people who pass by the restaurant or food establishment less interested in eating there.

Furthermore, the increased use of meal delivery apps will drop employee numbers in some businesses. Because the food is produced in the kitchen and delivered to the runner, the employer does not need more staff. To increase profits, the employer concentrates on boosting online customers, food preparation, and food packaging. Dish service may not be required if there is a runner to deliver the food to the consumer. The runner will provide the meal to the customer using company-provided transportation because all of the food delivery apps already have a runner to deliver the food; thus, the restaurant owner does not require any additional staff and may cut it. Meal safety is also vital in food delivery. The consumer has no idea how the food was prepared or stored when they used meal delivery applications. The worker or runner may not be aware of proper food handling procedures, resulting in food contamination. Because food is prepared in large quantities and then delivered to the customer's door via meal delivery, the food temperature may be altered, and the packaging used may result in food deterioration. The worker must first pack the meal before it can be delivered. Restaurant employees may be spreading foodborne diseases (FBD) to customers, whether they are aware of it or not. According to Hsiao et al. (2016), unmanaged food processing, packaging, and transferring among small online food sellers could increase the danger of food contamination and contribute to food poisoning outbreaks by allowing the growth of numerous harmful bacteria. The primary objectives of the study are to look into consumers' attitudes, satisfaction, and awareness of food safety, as well as consumers' intent to purchase food using meal delivery apps on Penang Island. This study was conducted on Penang Island.

\section{MATERIALS AND METHODS}

This study was conducted in Penang. The respondents for this study were chosen from among meal delivery app users in Penang who had prior experience with the apps. Respondents helped to collect data on customer attitudes, satisfaction, purchase intent, and food safety awareness regarding online food ordering via food delivery apps. The respondents were given a six-part questionnaire, which was used to conduct quantitative research.

Respondents in this study were given a series of bilingual questionnaires (Malay \& English). The questionnaire consists of closed-ended questions to which respondents must choose an answer from a list of options (Johnson \& Christensen, 2013). The questionnaire is divided into sections A (Sociodemographic profile), B (Use of food delivery apps), $\mathrm{C}$ (Consumer attitude), D (Consumer satisfaction), E (Consumer Purchase Intention), and F (Consumer Purchase Intention) (Awareness of Food Safety). Purposive sampling is a non-probability sampling in which a sample is selected based on population characteristics and the study's goal. The researcher's discretionary decision to select respondents is nonprobability sampling (Saunders et al., 2009). Purposive sampling is also known as judging, selective, or subjective sampling. The Statistical Package for Social Science (SPSS) version 20 was the leading program to analyze the data based on the study's goal. The normalcy test was used as the first test. Next, the Kolmogorov-Smirnov test was used as the normality test because the sample size was greater than $50(n>50)$. If the data obtained after analysis is normal, the parametric test will be used, $p<0.05$. If the data is not normal, a non-parametric test will be run to analyze it. The descriptive test was then used to extract the frequencies, percentages, mean, mode, and standard deviation from the sociodemographic profile. This exam calculated gender, age, religion, race, education level, occupation, and

Table 1. Section and type of question

\begin{tabular}{llc}
\hline Section and Purpose & Scale & $\begin{array}{c}\text { Number of } \\
\text { Question }\end{array}$ \\
\hline Section A: Socio-demographic profile & - Nominal scale & 8 items \\
Section B: Usage of food delivery apps & - Interval Scale (5 points Likert type scale) & 21 items \\
Section C: Consumers' attitude & - Interval Scale (5 points Likert type scale) & 9 items \\
Section D: Consumers' satisfaction & - Interval Scale (5 point Likert type scale) & 11 items \\
Section E: Consumers' purchase intention & - Interval Scale (5 points Likert type scale) & 8 items \\
Section F: Consumers' awareness of food safety & - Interval Scale (5 points Likert type scale) & 10 items \\
\hline
\end{tabular}


monthly income. In this study, the Mann-Whitney $\mathrm{U}$ test and Pearson correlation were also used. The entire experiment was designed to determine Penang consumer attitudes, satisfaction, purchase intent, and food safety awareness regarding meal delivery applications. The second goal was to look into the relationship between consumers' attitudes, satisfaction, food safety awareness, and purchase intent regarding food delivery apps in Penang. The third goal is to compare consumer attitudes, satisfaction, purchase intent, and food safety awareness regarding meal delivery applications across demographic groups.

\section{RESULTS AND DISCUSSION}

\section{Demographic profile of respondents}

Table 2 shows the demographic profile or characteristics of the respondent. The total number of respondents of this study was 160 respondents.

The descriptive test was used to determine the frequency and percentage of respondents in the demographic profile study. Table 2 shows that out of 160 respondents, 61 (38.1\%) identified themselves as male and $99(61.9 \%)$ as female. As a result, the female response rate is slightly higher than the male. It demonstrates that females make up the majority of

Table 2. Demographic characteristics of respondents

\begin{tabular}{|c|c|c|}
\hline Demographic characteristic & Frequency $(N=160)$ & Percentage (\%) \\
\hline \multicolumn{3}{|l|}{ Gender } \\
\hline Male & 61 & 38.1 \\
\hline Female & 99 & 61.9 \\
\hline \multicolumn{3}{|l|}{ Age } \\
\hline Between 10-17 & 3 & 1.9 \\
\hline Between 18-25 & 121 & 75.6 \\
\hline Between 26-35 & 24 & 15.0 \\
\hline Between 36-45 & 8 & 5.0 \\
\hline Between 46-55 & 4 & 2.5 \\
\hline \multicolumn{3}{|l|}{ Religion } \\
\hline Islam & 135 & 84.4 \\
\hline Buddhism & 10 & 6.3 \\
\hline Hinduism & 6 & 3.8 \\
\hline Christianity & 9 & 5.6 \\
\hline \multicolumn{3}{|l|}{ Race } \\
\hline Malay & 133 & 83.1 \\
\hline Chinese & 19 & 11.9 \\
\hline Indian & 7 & 4.4 \\
\hline Siamese & 1 & 0.6 \\
\hline \multicolumn{3}{|l|}{ Marital status } \\
\hline Single & 138 & 86.3 \\
\hline Married & 22 & 13.8 \\
\hline \multicolumn{3}{|l|}{ Education level } \\
\hline Lower secondary Assessment & 3 & 1.9 \\
\hline Malaysian Certificate of Education & 27 & 16.9 \\
\hline Malaysian Higher Education Certificate & 9 & 5.6 \\
\hline Diploma & 32 & 20.0 \\
\hline Degree & 85 & 53.1 \\
\hline Master & 2 & 1.3 \\
\hline Malaysian Skills Certificate & 2 & 1.3 \\
\hline \multicolumn{3}{|l|}{ Occupational } \\
\hline Private & 63 & 39.4 \\
\hline Government & 3 & 1.9 \\
\hline Student & 81 & 50.6 \\
\hline Housewife & 5 & 3.1 \\
\hline Unemployment & 8 & 5.0 \\
\hline \multicolumn{3}{|l|}{ Monthly income } \\
\hline Less than RM1500 & 107 & 66.9 \\
\hline RM1500-RM2999 & 30 & 18.8 \\
\hline RM3000-RM3999 & 7 & 4.4 \\
\hline RM4000-RM4999 & 5 & 3.1 \\
\hline RM5000-RM5999 & 7 & 4.4 \\
\hline RM6000 and above & 4 & 2.5 \\
\hline
\end{tabular}


the responder data set. They were divided into five groups based on their age range: 10-17 years old, 1825 years old, 26-35 years old, 36-45 years old, and 46-55 years old. The respondents between 18 and 25 had the highest percentage of respondents $(75.6 \%)$ with 121 respondents. With 24 votes, the group of 26-35 years old came in second $(15.0 \%)$. The other three age groups, $36-45$ years old $(5.0 \%), 10-17$ years old $(3.9 \%)$, and $46-55$ years old $(4.9 \%)$ showed no difference $(2.5 \%)$. Respondents hailed from four faiths: Islam, Buddha, Hinduism, and Christianity, according to the religious results. With 135 respondents, Islam was the most common religion $(84.4 \%)$. Christians received the second-highest number of responses (9). (5.6\%). Respondents who identify as Buddhists receive a score of ten (6.3\%). The respondents are Malay, Chinese, Indians, and Siamese, representing four different races. Malay people are the most likely to react $(133.1 \%)$, followed by Chinese (19.1\%). (11.9\%). Indians account for 7 $(4.4 \%)$ of the minority respondents, while Siamese accounts for one $(0.6 \%)$. This survey also inquired about marital status. The majority of the respondents are single, with $138(86.3 \%)$, and the number of married people is $22(13.8 \%)$. Following that, the highest educational level is a Bachelor's degree, which has an $85 \%$ reading rate $(53.1 \%)$. The Diploma and MCE came in second and third, with $32(20.0 \%)$ and $27(16.9 \%)$, respectively. MHEC has 9 (5.6\%), Master has $2(1.3 \%)$, LSA has $3(1.9 \%)$, and MSC has two respondents with the highest education (1.3\%). Aside from that, there are five types of jobs: private, government, students, housewives, and unemployed. With $81(50.6 \%)$, students were the most likely to reply in this survey, followed by the private sector with $63(39.4 \%)$. Unemployment accounted for 8 (5.0\%), housewives for $5(3.1 \%)$, and the government for 3 of the remaining respondents $(1.9 \%)$. The respondents' monthly income was separated into six categories: under RM1500, between RM1500 and RM2999, between RM3000 and RM3999, between RM4000 and RM4999, between RM5000 and RM5999, and between RM6000 and above. The income category with the most respondents was less than RM1500, with 107 (66.9\%), followed by RM1500RM2999, with 30 (18.8\%), and RM3000-RM3999, with 7. (4.4\%). The remaining categories were categorized as follows: RM4000-RM4999 5 (3.1\%), RM5000RM5999 7 (4.4\%), and RM6000 and above 4 (4.4\%). (2.5\%).

\section{Respondents learn about meal delivery apps from a variety of sources}

The percentage of sources respondents found for meal delivery apps is shown in Figure 1. Friends, relatives, social media, advertisements, and promotion fliers are the five different ways respondents learn about meal delivery applications. With $55.6 \%$ of respondents, social media was the most common source of information regarding meal delivery applications. Friends and advertisements came in second and third, with $19.4 \%$ and $17.5 \%$, respectively. Because of societal pressure, the least amount of money comes from family and promotion fliers, at $6.3 \%$ and $1.3 \%$, respectively. The impact of friends, colleagues, family, the media, and society on adopting an objective is societal pressure. Advertisements on food delivery apps from various

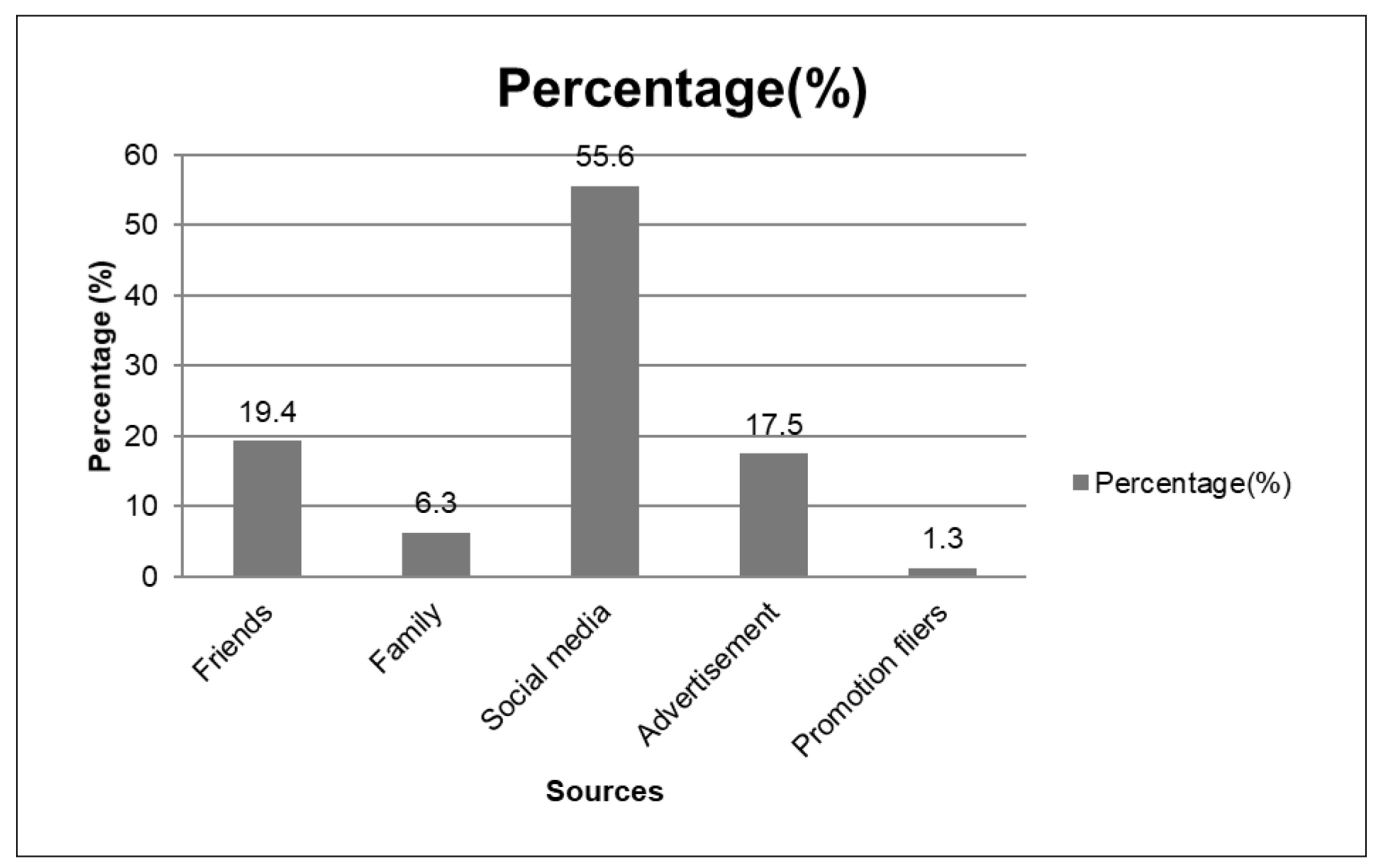

Fig. 1. Shows the percentage of sources respondent finds about food delivery apps. 
sources, such as the media, friends, and peers, can be used to identify societal pressure. According to Dang et al. (2018), online social networks have become one of the most popular places to look for food products because food companies on social media sites are visited by a vast number of people (Freeman et al., 2014). This phenomenon could be explained by the exponential increase in social media users and how social media helps people expand their communication networks. Consumers are also influenced by their friends when ordering food online through restaurant delivery applications. People who are more easily persuaded by others will trust their friends' choices and experiences when they share, post illustrative photographs, or review food products on social media (Freeman et al., 2014).

Based on usage, Table 3 demonstrates that Grab Meal, Food Panda, and DeliverEat are the most popular food delivery applications in Penang. Meanwhile, FoodLab Express, Eat Fit, and Deliver Monster received the lowest grades because they were not well-known among the respondents. According to Morganti and Gonzalez-Feliu (2015), the delivery size (small) and frequency (high) of these schemes, as well as a network organization, are the critical challenges to their successful implementation (a large number of receivers spread throughout the city). Food delivery apps with small delivery sizes are pretty popular because they can send a large amount of food to a customer for less money and time when they choose to deliver in small sizes. Next, customers are attracted to high frequency because, when there are enough workers for delivery, the client does not have to wait to get their order. After all, the frequency is high. Finally, many connections imply that the delivery app firm offers a wide range of food options from various food and beverage establishments and is available in many locations across the country. As a result, the popularity and consumer demand for food delivery services grow (Li et al., 2020).

\section{Consumers' attitude}

Nine items are measured when it comes to customer attitudes concerning meal delivery applications. Table 4 shows that the median for the majority of the measurement items is 4 . The majority of respondents agreed with all of the statements. The median score for measurement item number 8, "I believe that buying meals through food delivery apps saves more money," is 3 , indicating neutral or not sure. It reveals that most respondents are unsure if food delivery apps may save them money and frequently compare the cost of food delivery apps to the cost of food from a stall or restaurant. The question "I believe that food delivery apps can save me time" had a median score of 4 , indicating that the majority of respondents agree that food delivery apps may save time. Consumers' attitudes about food delivery apps improve when they save time, according to prior research by Eriksson and Nilsson (2007). They found that saving time enhances attitudes through the simplicity of use and usefulness. Therefore, consumers are more likely to use meal delivery applications when they can save time.

\section{Consumers' satisfaction}

There are a total of 11 measuring items in the consumer satisfaction segment. The median of the questionnaire is shown in Table 5. Half of the measuring items got a median score of 4 as a result

Table 3. Shows the most popular food delivery apps

\begin{tabular}{|c|c|c|}
\hline Food delivery apps & $\begin{array}{l}\text { Frequency } \\
(N=160)\end{array}$ & $\begin{array}{c}\text { Percentage } \\
\quad(\%)\end{array}$ \\
\hline \multicolumn{3}{|l|}{ DeliverEat } \\
\hline Never & 56 & 35.0 \\
\hline Seldom & 56 & 35.0 \\
\hline Sometimes & 20 & 12.5 \\
\hline Often & 16 & 10.0 \\
\hline Very often & 12 & 7.5 \\
\hline \multicolumn{3}{|l|}{ Food Panda } \\
\hline Never & 27 & 16.9 \\
\hline Seldom & 58 & 36.3 \\
\hline Sometimes & 34 & 21.3 \\
\hline Often & 20 & 12.5 \\
\hline Very often & 21 & 13.1 \\
\hline \multicolumn{3}{|l|}{ Grab Food } \\
\hline Never & 43 & 26.9 \\
\hline Seldom & 54 & 33.8 \\
\hline Sometimes & 29 & 18.1 \\
\hline Often & 12 & 7.5 \\
\hline Very often & 22 & 13.8 \\
\hline \multicolumn{3}{|l|}{ FoodLab Express } \\
\hline Never & 132 & 82.5 \\
\hline Seldom & 23 & 14.4 \\
\hline Sometimes & 5 & 3.1 \\
\hline \multicolumn{3}{|l|}{ Eat Fit } \\
\hline Never & 136 & 85.0 \\
\hline Seldom & 18 & 11.3 \\
\hline Sometimes & 6 & 3.8 \\
\hline \multicolumn{3}{|l|}{ Delivery Monster } \\
\hline Never & 134 & 83.8 \\
\hline Seldom & 23 & 14.4 \\
\hline Sometimes & 3 & 1.9 \\
\hline \multicolumn{3}{|l|}{ FoodLab Express } \\
\hline Never & 132 & 82.5 \\
\hline Seldom & 23 & 14.4 \\
\hline Sometimes & 5 & 3.1 \\
\hline \multicolumn{3}{|l|}{ Eat Fit } \\
\hline Never & 136 & 85.0 \\
\hline Seldom & 18 & 11.3 \\
\hline Sometimes & 6 & 3.8 \\
\hline \multicolumn{3}{|l|}{ Delivery Monster } \\
\hline Never & 134 & 83.8 \\
\hline Seldom & 23 & 14.4 \\
\hline
\end{tabular}


Table 4. Median of consumers' attitude towards food delivery apps in Penang

\begin{tabular}{|c|c|c|}
\hline No & Measurement item & $\begin{array}{c}\text { Median } \\
(\text { IQR) }\end{array}$ \\
\hline 1. & I believe that food delivery apps are suitable for me. & $4.00(1)$ \\
\hline 2. & I think that food delivery apps are helpful for limited time people. & $4.00(1)$ \\
\hline 3. & I believe that food delivery apps can save me time. & $4.00(2)$ \\
\hline 4. & I believe that using food delivery apps is very useful in the purchasing process. & $4.00(1)$ \\
\hline 5. & I believe that food delivery apps provide an excellent service to the consumer. & $4.00(1)$ \\
\hline 6. & I believe that food delivery apps offer a lot of food choices. & $4.00(1)$ \\
\hline 7. & I believe that using food delivery apps helps me accomplish things more quickly in the purchasing process. & $4.00(1)$ \\
\hline 8. & I believe that buying food through food delivery apps saves more money. & $3.00(2)$ \\
\hline 9. & Using mobile food order apps increases my chances of achieving tasks that are important to me. & $4.00(1)$ \\
\hline
\end{tabular}

*Note: Median based on 5-point Likert scale ( $1=$ strongly disagree to $5=$ strongly agree)

*Median is the middle value of the lower and upper half of the data

${ }^{*}$ IQR (1) = score more towards the upper value of data

${ }^{*} \mathrm{IQR}(2)=$ score more towards the lower value of data

Table 5. Median of consumers' satisfaction towards food delivery apps in Penang

\begin{tabular}{|c|c|c|}
\hline No & Measurement item & $\begin{array}{c}\text { Median } \\
(\text { IQR) }\end{array}$ \\
\hline 1. & In general, I am satisfied with the arrangement of the apps when making an order. & $3.00(1)$ \\
\hline 2. & The delivery charge provided by the food delivery apps is affordable. & $3.00(1)$ \\
\hline 3. & I am satisfied with the runner service when delivering my food. & $4.00(1)$ \\
\hline 4. & Waiting time for the food and drink to be delivered is not too long. & $3.00(1)$ \\
\hline 5. & The arrangement and design of the food delivery apps are excellent. & $3.00(1)$ \\
\hline 6. & Food and drinks were received as ordered. & $4.00(1)$ \\
\hline 7. & I am satisûed with the way that mobile food order apps have carried out transactions. & $4.00(1)$ \\
\hline 8. & The overall quality of food and drinks received is good. & $3.50(1)$ \\
\hline 9. & $\begin{array}{l}\text { The information provided in online reviews of mobile food order apps was helpful for me to } \\
\text { evaluate the product. }\end{array}$ & $4.00(1)$ \\
\hline 10. & I am happy with mobile food order apps. & $4.00(1)$ \\
\hline 11. & I am satisfied with the overall service provided by the food-to-deliver apps. & $4.00(1)$ \\
\hline
\end{tabular}

*Note: Median based on 5-point Likert scale ( $1=$ strongly disagree to $5=$ strongly agree)

*Median is the middle value of the lower and upper half of the data

${ }^{*} \mathrm{IQR}(1)=$ score more towards the upper value of data

${ }^{*} \mathrm{IQR}(2)=$ score more towards the lower value of data

of the analysis. It means that half of the people who responded agreed with the assertion made in this Section. On the other hand, the median score of 3 indicates that roughly half of the respondents did not agree on some of the features, such as app arrangement, delivery charges, waiting time, and overall food quality, because the respondents were not satisfied with the delivery. According to Kim et al. (2013), there is a favorable association between delivery experience and purchase intent. A positive experience can lead to a desire to utilize or reuse a service again. As a result, the respondents may not have had a good or excellent experience with meal delivery apps in this situation, lowering their happiness. Furthermore, consumers do not appreciate free delivery or punctual delivery of food while utilizing food delivery apps, according to $\mathrm{Li}$ et al. (2020), because the delivery runner is frequently late due to road traffic in most cities. The fact that the applications' layout and design have a median score of 3 indicates that respondents do not find the apps appealing enough to make them agree with the statement.

Compared to traditional retail locations, these apps or websites must be attractive (Dawson \& Kim, 2010). Its cues influence affective and cognitive internal states. The online review received a median score of 4 , indicating that customers like to read online reviews before purchasing food. According to Engler et al. (2015), customer reviews are one of the most potent elements influencing consumers' online purchase decisions. Consumers can leave reviews on online retailers' websites to express their thoughts and experiences with the things they've purchased. As a result of these reviews, more customers are drawn to the company, and future customers can make more informed decisions (Cao et al., 2011). The median score for the item "I am content with how 
mobile food order apps have handled transactions" is 4 , indicating that respondents were satisfied with the transactions while ordering meals through restaurant delivery apps. According to AudrainPontevia et al. (2013), online transactions provide transaction value for users because they can buy things after comparing them to other offers.

\section{Consumers' awareness of food safety}

The total number of measuring items for consumer food safety knowledge is ten. The median score for the majority of the items in Table 6 is 4 . It means that everyone who responded agreed with the statement. But for questions, numbers 2 and 4 had a median score of 3 . It implies that the respondents are unaware that eating food from a delivery service can cause food illness and have reservations about the cleanliness of the vehicle used to carry their food. According to Table 6, respondents were willing to learn more about food safety. According to Dang et al. (2018), this is beneficial because customers are frequently misled by online advertising information that competent authorities cannot validate, creating concerns about food safety and foodborne infections.

\section{Consumers' purchase intention}

The consumer's purchase intention part follows, with a total of eight measurement elements. Table 7 shows that, in contrast to the other sections, this one has the most measurement elements, with a median of 3 , indicating neutral or unsure. The majority of respondents do not agree or disagree with the statements in the Section on purchasing intentions. The only three measurement items with a median of 4, number two, four, and six, indicate that respondents will only use meal delivery apps if they cannot buy food directly due to time or job constraints. It shows that they will order more meals through delivery apps in the future, even if it is not necessary. Furthermore, this could occur due to personal innovation in the field of information technology (PIIT). Consumer attitudes toward new technology linked to PIIT. According to (Lien, 2017),

Table 6. Median of consumers' awareness of food safety when using food delivery apps

\begin{tabular}{llr}
\hline No & Measurement item & $\begin{array}{c}\text { Median } \\
(\text { IQR })\end{array}$ \\
\hline 1. I notice that food delivered from the food delivery apps is always covered correctly. & $4.00(1)$ \\
2. I am aware that I can also get food poisoning from eating food through online food delivery. & $3.00(1)$ \\
3. I observe the cleanliness of food ordered from online food delivery. & $4.00(1)$ \\
4. I am sure that the transport used by the food delivery worker is clean and safe. & $3.00(1)$ \\
5. I know not to eat food that has deteriorated and exceeded its shelf life. & $4.00(2)$ \\
6. I am aware of food safety incidents or issues in recent years in our country. & $4.00(1)$ \\
7. I am concerned about the transfer of plasticizers in food containers and packaging materials. & $4.00(1)$ \\
8. I am willing to improve my knowledge of food safety. & $4.00(2)$ \\
9. I always look at the characteristics of food when receiving it. & $4.00(1)$ \\
10. When encountering food safety problems, require the complaint to the relevant departments. & $4.00(2)$ \\
\hline
\end{tabular}

*Note: Median based on 5-point Likert scale ( $1=$ strongly disagree to $5=$ strongly agree)

*Median is the middle value of the lower and upper half of the data

${ }^{*} \mathrm{IQR}(1)=$ score more towards the upper value of data

${ }^{*} \mathrm{IQR}(2)=$ score more towards the lower value of data

Table 7. Median of consumers' purchase intention towards food delivery apps in Penang

\begin{tabular}{|c|c|c|}
\hline No & Measurement item & $\begin{array}{c}\text { Median } \\
(\text { IQR) }\end{array}$ \\
\hline 1. & I will purchase food through a food delivery service because their promotional plan is attractive. & $3.00(1)$ \\
\hline 2. & I will purchase food through delivery apps because it is easy to access at my workplace. & $4.00(1)$ \\
\hline 3. & Whenever I need to buy food, I likely will purchase from the food delivery apps. & $3.00(1)$ \\
\hline 4. & I will purchase food through food delivery apps every time I am busy. & $4.00(1)$ \\
\hline 5. & I will purchase food through delivery apps because the food is a good product for the price. & $3.00(1)$ \\
\hline 6. & I will purchase food through food delivery apps in the future. & $4.00(1)$ \\
\hline 7. & I will always try to use mobile food order apps in my daily life. & $3.00(1)$ \\
\hline 8. & I plan to continue to use mobile food order apps frequently. & $3.00(1)$ \\
\hline
\end{tabular}

*Note: Median based on 5-point Likert scale (1=strongly disagree to $5=$ strongly agree)

*Median is the middle value of the lower and upper half of the data

${ }^{*} \mathrm{QQR}(1)=$ score more towards the upper value of data

${ }^{*}$ IQR $(2)$ = score more towards the lower value of data 
Table 8. Correlation between consumers' attitude, satisfaction, awareness of food safety, and purchase intention

\begin{tabular}{lccc}
\hline & Consumers' attitude & Consumers' satisfaction & Awareness of food safety \\
\hline Consumers' attitude & & & \\
Consumers' satisfaction & $0.695^{* *}$ & $0.708^{* *}$ & $0.618^{* *}$ \\
Awareness of food safety & $0.661^{* *}$ & $0.650^{* *}$ \\
Purchase intention & $0.621^{* *}$ & \\
\hline
\end{tabular}

Spearman correlation test was used

** Correlation is significant at the 0.01 level (2-tailed)

$r$-value, $0.7-0.9=$ strong relationship

$r$-value, $0.4-0.69=$ moderate relationship

Table 9. Guilford's rule of thumb

\begin{tabular}{ll}
\hline Pearson's coefficient, $r$ & Strength of relationship \\
\hline$<0.2$ & Almost no relationship \\
$0.2-0.39$ & Weak relationship \\
$0.4-0.69$ & Moderate relationship \\
$0.7-0.9$ & Strong relationship \\
$>0.9$ & Very strong relationship \\
\hline
\end{tabular}

PITT has a beneficial impact on consumers' attitudes towards online purchases. Because meal delivery apps are a new technology growing in popularity, some users are hesitant to test them because they are accustomed to the old way of purchasing food and beverages on their own. The median score for the statement "I will purchase meals through a food delivery service since their promotional plan is appealing" was 3, indicating that the respondents were neutral about the statement. It could be since they did not find the apps appealing enough to agree with the statement. According to Nusair et al. (2010), price-sensitive customers are more inclined to choose the channel that gives them the most value for money.

Relationship between consumers' attitude, satisfaction, awareness of food safety, and food purchase intention through food delivery apps.

Table 8 shows the relationship between consumers' attitude, satisfaction, awareness of food safety, and food purchase intention through food delivery apps. For all the relationships, the result is discussed based on using Guilford's rule of thumb.

The correlation coefficient was discovered to be $0.695(r=0.695)$. According to Guilford's rule of thumb, there is a moderate association between customer attitude and satisfaction because the value must not exceed 0.7 to be considered strong. Next, there's the link between consumer attitudes and food safety awareness. The correlation value was 0.661 $(r=0.661)$, indicating a moderately positive association between consumer attitudes and food safety awareness. The third relationship is that between a consumer's attitude and their intention to buy. The correlation coefficient is equal to 0.621 $(r=0.621)$. Because the number is in the range of 0.4 0.69 , it is likewise considered a moderate connection. The online purchase experience is a significant component that influences attitudes and the desire to purchase (Weisberg et al., 2011). The correlation coefficient between consumer happiness and food safety knowledge is $0.708(r=0.708)$. The link between consumer happiness and food safety awareness is high because the value is $0.7-0.9$. The remaining two correlations are between customer satisfaction and purchasing intent and food safety awareness and purchasing intent. The relationship's coefficients of correlation were $0.618(r=0.618)$ and $0.650(r=0.650)$, respectively.

Comparison of socio-demographic profile with consumer attitudes, satisfaction, food safety awareness, and food purchase intent for food ordered through food delivery apps.

Table 10 compares a socio-demographic profile's mean rank and $p$-value to consumer attitudes, satisfaction, food safety awareness, and purchase intent for food bought through food delivery apps. Mann-Whitney The $U$ test is used to compare two groups' socio-demographic characteristics. The null hypothesis is rejected first, and the alternative hypothesis is accepted to determine a potential association. The null hypothesis is rejected, and the alternative hypothesis is accepted if the $p$-value is less than 0.05 . As a result, they are vastly dissimilar. There is a significant difference between age groups and purchase intention, as the p-value for those aged 25 and under is $(p=0.001)$. The five age groups of 10-17 years old, 18-25 years old, 26-35 years old, 3645 years old, and $46-55$ years old were divided into only two categories: young people and adults because respondents for age groups 10-17 years old and $46-55$ years old were too small and difficult to analyze.

The following finding is a statistically significant link between marital status and meal delivery app purchase intention $(p=0.023)$. It reveals that there is a significant difference between single people and married people. There's also a link between occupation and consumer attitude $(p=0.025)$ and occupation and food safety awareness $(p=0.032)$. 
Table 10. Comparison between socio-demographic profile with consumers' attitude, satisfaction, awareness of food safety, and purchase intention

\begin{tabular}{|c|c|c|c|c|c|c|c|c|}
\hline \multirow[t]{2}{*}{ Item } & \multicolumn{2}{|c|}{$\begin{array}{l}\text { Consumer } \\
\text { attitude }\end{array}$} & \multicolumn{2}{|c|}{$\begin{array}{c}\text { Consumer } \\
\text { satisfaction }\end{array}$} & \multicolumn{2}{|c|}{$\begin{array}{l}\text { Awareness of } \\
\text { food safety }\end{array}$} & \multicolumn{2}{|c|}{$\begin{array}{l}\text { Purchase } \\
\text { intention }\end{array}$} \\
\hline & Mean rank & $p$-value & Mean rank & $p$-value & Mean rank & $p$-value & Mean rank & $p$-value \\
\hline \multicolumn{9}{|l|}{ Gender } \\
\hline Male & 76.57 & 0.399 & 76.03 & 0.337 & 74.04 & 0.165 & 81.72 & 0.793 \\
\hline Female & 82.92 & & 83.25 & & 84.48 & & 79.75 & \\
\hline \multicolumn{9}{|l|}{ Race } \\
\hline Malay & 81.07 & 0.730 & 81.24 & 0.651 & 80.23 & 0.871 & 78.51 & 0.225 \\
\hline Non Malay & 77.70 & & 76.83 & & 81.81 & & 90.31 & \\
\hline \multicolumn{9}{|l|}{ Age } \\
\hline$\leq 25$ years & 77.81 & 0.172 & 77.99 & 0.202 & 77.18 & 0.091 & 74.04 & 0.001 \\
\hline$\geq 26$ years & 89.75 & & 89.14 & & 91.94 & & 102.76 & \\
\hline \multicolumn{9}{|l|}{ Marital status } \\
\hline Single & 79.52 & 0.501 & 80.14 & 0.806 & 79.02 & 0.310 & 77.20 & 0.023 \\
\hline Married & 86.66 & & 82.c75 & & 89.77 & & 101.23 & \\
\hline \multicolumn{9}{|l|}{ Education level } \\
\hline School & 90.72 & 0.112 & 83.21 & 0.674 & 79.71 & 0.902 & 88.00 & 0.243 \\
\hline University & 77.21 & & 79.63 & & 80.76 & & 78.08 & \\
\hline \multicolumn{9}{|l|}{ Occupation } \\
\hline Working & 90.27 & 0.025 & 85.20 & 0.280 & 89.81 & 0.032 & 88.37 & 0.070 \\
\hline Un-employment & 73.64 & & 77.20 & & 73.96 & & 74.97 & \\
\hline \multicolumn{9}{|l|}{ Monthly income } \\
\hline$<$ RM3000 & 78.19 & 0.122 & 79.05 & 0.334 & 78.17 & 0.119 & 76.29 & 0.005 \\
\hline >RM3000 & 94.26 & & 89.11 & & 94.37 & & 105.57 & \\
\hline
\end{tabular}

Man-Whitney $U$ test used

*Indicate significant differences mean rank at the 0.05 level

If $p$-value $<0.05$, there is a significant difference between the two variables

If $p$-value $>0.05$, there is no significant difference between the two variables

Finally, there is a significant difference between monthly income and customer purchase intentions $(p=0.1005)$. Low income was defined as less than RM3000, and high income was defined as more than RM3000. There is no substantial relationship between gender and consumer attitudes, satisfaction, food safety awareness, or food purchase intent, and there is also no significant relationship between race and consumer attitudes, satisfaction, food safety awareness, or purchase intent. There were five races: Malays, Chinese, Indians, and Siamese, subsequently divided into two groups: Malay and Non-Malay. The number of Malay responses was far too significant to compare with the results of other races when only two groups were considered. There is no significant relationship between age and customer attitudes, satisfaction, or food safety awareness. There is also no link between marital status and customer attitudes, contentment, or food safety awareness.

Furthermore, there is no link between education level and consumer attitudes, contentment, food safety awareness, or purchase intent. Then there's no tangible link between occupation and consumer pleasure, as well as occupation and buying intent.
Last but not least, there is no correlation between monthly income and consumer attitudes, satisfaction, food safety awareness, or purchase intent. Saad et al. (2013) discovered no significant associations between food safety knowledge scores and income, educational level, age, or previous food safety courses.

\section{CONCLUSION}

When it comes to consumer attitudes, the majority of respondents agree with the statement in that Section. Furthermore, half of the respondents agree with the statement regarding consumer satisfaction, while the other half are undecided. Most respondents agree with the statement regarding consumer awareness of food safety, except that they are unaware of food poisoning and have reservations about the cleanliness of the transportation used to deliver the food. Next, when it comes to consumers' purchase intentions, the majority of respondents are undecided. Meanwhile, there is a strong link between consumer satisfaction and food safety awareness. Dang et al. (2018) back this up, stating that there 
were no significant differences in all variables between male and female food product consumers. Dang et al. (2018) support the notion that females are more concerned about food hygiene than males because they are the primary food preparers in the household. Due to the increase in working females, males are now also involved in home food preparation. There is a significant difference between age and consumers' purchase intention and a significant difference between marital status and consumers' purchase intention, with p-values of $(p=0.001)$ and $(p=0.023)$, respectively, in the sociodemographic relationship. According to Ruby et al. (2019), the age group is divided into two categories: under 25 years old is considered a youth, and 26 years and up is considered an adult. It is not difficult to place an order for food on the internet. It can be done by many people, especially since most of the respondents are younger people who are more familiar with technology (Jiang et al., 2013). As a result, there is a significant difference in purchase intentions by age group. Then, with $p$-values of $(p=0.025)$ and $(p=0.032)$, there is a significant difference between occupation with attitude plus occupation and consumers' awareness of food safety. Privates, the government, students, homemakers, and unemployed people are the five types of occupations.

Nonetheless, the number of responders for the government and homemakers is modest. As a result, the categories were consolidated into private and government employment and unemployment for students, homemakers, and the unemployed. Finally, there is a considerable difference between monthly income and consumers' meal delivery app purchase intentions. Thus, we may conclude from this study that consumer attitudes, satisfaction, and food safety awareness all play a part in meal delivery apps.

\section{ACKNOWLEDGEMENTS}

We would like to express our gratitude to the Faculty of Fisheries and Food Science at Universiti Malaysia Terengganu and the Faculty of Health Sciences, Department of Nutrition \& Dietetics at Universiti Sultan Zainal Abidin for their assistance with this research.

\section{REFERENCES}

Audrain-Pontevia, A.-F, N'Goala, G. \& Poncin, I. 2013. A good deal online: The impacts of acquisition and transaction value on esatisfaction and e-loyalty. Journal of Retailing and Consumer Services, 20(5): 445-452.
Cao, Q., Duan, W. \& Can, Q. 2011. Exploring determinants of voting for the 'helpfulness' of online user reviews: a text mining approach. Decision Support System, 50: 511-521.

Dang, A.K., Tran, B.X., Nguyen, C.T., Le, H.T., Do, H.T., Nguyyen, H.D., Nguyen, L.H., Nguyen, T.H., Mai, H.T., Tran, T.D., Ngo, C., Vu, T.T.M., Latkin, C.A., Zhang, M.W.B. \& Ho, R.C.M. 2018. Consumer preference and attitude regarding online food products in Hanoi, Vietnam. International Journal of Environmental Research and Public Health, 15(5): 5-8.

Dawson, S. \& Kim, M. 2010. Cues on apparel websites that trigger impulse purchases. Journal of Fashion Marketing and Management: An International Journal, 14(2): 230-246.

Engler, T.H., Winter, P. \& Schulz, M. 2015. Understanding online product ratings: A customer satisfaction model. Journal of Retailing and Consumer Services, 27: 113-120.

Eriksson, K. \& Nilsson, D. 2007. Determinants of the continued use of self-service technology: The case of Internet banking. Technovation, 27(4): 159-167.

Freeman, B., Kelly, B., Baur, L., Chapman, K., Chapman, S., Gill, T. \& King, L. 2014. Digital junk: Food and beverage marketing on Facebook. American Journal of Public Health, 104: e56-e64.

Hsiao, H.I., Jan, M.S. \& Chi, H.J. 2016. Impacts of climatic variability on vibrio parahaemolyticus outbreaks in Taiwan. International Journal of Environmental Research and Public Health, 13: 188.

Jiang, L.A., Yang, Z. \& Jun, M. 2013. Measuring consumer perceptions of online shopping convenience. Journal of Service Management, 24(2): 191-214.

Johnson, R.B. \& Chritensen, L. 2013. Educational Research: Qualitative, Qualitative and Mixed Approaches. Sage Publication, New York. 199 pp.

Kapoor, A.P. \& Vij, M. 2018. Technology at the dinner table: Ordering food online through mobile apps. Journal of Retailing and Consumer Services, 43: 342-351.

Kim, J. \& Lennon, S.J. 2013. Effects of reputation and website quality on online consumers' emotion, perceived risk and purchase intention: Based on the stimulus organism response model. Journal of Research in Interactive Marketing, 7(1): 3356.

Li, C., Mirosa, M. \& Bremer, P. 2020. Review of online food delivery platforms and their impacts on sustainability. Sustainability, 12(14): 5528. 
Lien, T. 2017. How food delivery apps have changed the game for restaurants [WWW Document]. Los Angeles Times. URL http://www.latimes. com/busines s / t e chnology/la - fi - tn apprestaurants- 20170313-story.html (accessed 3.13.19).

Morganti, E. \& Gonzalez-Feliu, J. 2015. The last food mile concept as a city logistics solution for perishable products. In Enterprise Interoperability: Interoperability for Agility, Resilience and Plasticity of Collaborations: I-ESA'14 Proceedings. M. Lauras, M. Zelm, B. Archimède, F. Bénaben and G. Doumeingts (Eds.). pp. 202-207.

Nusair, K., Hae J.Y., Naipaul, S. \& Parsa, H.G. 2010. Effect of price discount frames and levels on consumers' perceptions in low-end service industries. International Journal of Contemporary Hospitality Management, 22(6): 814835 .
Ruby, G.E., Ungku Zainal Abidin, U., Lihan, S., Jambari, N. \& Radu, S. 2019. A cross-sectional study on food safety knowledge among adult consumer. Food Control, 99: 98-105.

Saad, M., Toh, P.S. \& Mohamed Adil, M.A. 2013. Hygiene practices of food handlers at the Malaysian Government institutions training centers. Procedia - Social and Behavioral Sciences, 85: 118-127.

Saunders, M., Lewis, P. \& Thornhill, A. 2009. Research Methods for Business Students. Pearson Education Limited, England.

Weisberg, J., Te'eni, D. \& Arman, L. 2011. Past purchase and intention to purchase in eCommerce: The mediation of social presence and trust. Internet Research, 21(1): 82-96. 
